\title{
High signal intensity on diffusion-weighted magnetic resonance images is a useful finding for detecting early-stage pancreatic cancer
}

\author{
Akira Kurita $^{1,3} \cdot$ Yoshiharu Mori $^{1} \cdot$ Yuko Someya $^{2} \cdot$ Shigeto Kubo $^{2} \cdot$ Shunjiro Azuma $^{1} \cdot$ Kosuke Iwano $^{1}$. \\ Satoshi Ikeda ${ }^{2} \cdot$ Ryosuke Okumura $^{2} \cdot$ Shujiro Yazumi $^{1}$
}

Received: 5 May 2021 / Revised: 24 June 2021 / Accepted: 26 June 2021 / Published online: 5 July 2021

(C) The Author(s) 2021

\begin{abstract}
Purpose Early detection of pancreatic ductal adenocarcinoma (PDAC) may improve the prognosis. We evaluated novel imaging findings that may contribute to early detection.

Methods This single-center, retrospective study enrolled 37 patients with a localized main pancreatic duct (MPD) stricture and no obvious pancreatic mass. All patients underwent endoscopic retrograde cholangiopancreatography and brush sampling with cytology and serial pancreatic juice aspiration cytologic examination via endoscopic naso-pancreatic drainage. Patients with cytology-confirmed malignancy underwent surgical resection. The remaining patients were followed by contrast-enhanced computed tomography (CECT), magnetic resonance imaging (MRI), and endoscopic retrograde cholangiopancreatography.

Results Twenty patients had confirmed malignancy (cancer group) and 17 did not (non-cancer group). Age, MPD stricture location, and PDAC risk factors were similar, but the sex predominance and symptom rate differed between the two groups. In the cancer group, 17 patients were diagnosed by cytology and three by clinical symptoms. CECT, MRI, and endoscopic ultrasonography (EUS) revealed no solid tumors in either group. CECT revealed no significant differences between groups. Diffusion-weighted MRI revealed significant differences in the signal intensity between groups. EUS detected indistinct and small hypoechoic areas in $70 \%$ and $41.2 \%$ of patients in the cancer and non-cancer groups, respectively. In the cancer group, 11 were diagnosed with cancer at the first indication, and nine were diagnosed at follow-up; the prognosis did not differ between these two subgroups.ss

Conclusions High signal intensity in diffusion-weighted MRI may be useful for detecting early-stage PDAC and may be an indication for surgical resection even without pathologic confirmation.

Clinical trial registration The study was a registered at the University Hospital Medical Information Network (UMIN000039623).
\end{abstract}

\section{Graphic abstract}

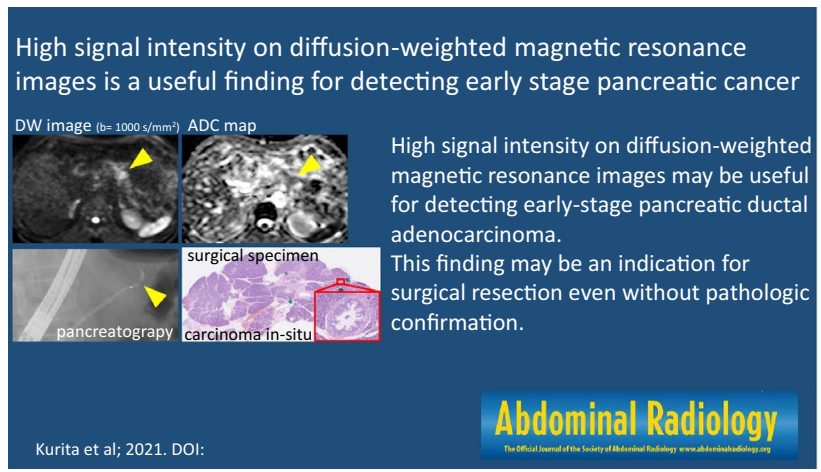

Keywords Pancreatic cancer - Early diagnosis - Diagnostic modality

Extended author information available on the last page of the article 


$\begin{array}{ll}\text { Abbreviations } \\ \text { ADC } & \text { Apparent diffusion coefficient } \\ \text { CECT } & \text { Contrast-enhanced computed tomography } \\ \text { CIS } & \text { Carcinoma in situ } \\ \text { CT } & \text { Computed tomography } \\ \text { DW } & \text { Diffusion weighted } \\ \text { DWI } & \text { Diffusion-weighted MRI } \\ \text { ENPD } & \text { Endoscopic naso-pancreatic drainage } \\ \text { ERC } & \text { Endoscopic retrograde } \\ & \text { cholangiopancreatography } \\ \text { EUS } & \text { Endoscopic ultrasonography } \\ \text { HRI } & \text { High-risk individual } \\ \text { IRB } & \text { Institutional review board } \\ \text { MDCT } & \text { Multidetector computed tomography } \\ \text { MPD } & \text { Main pancreatic duct } \\ \text { MR } & \text { Magnetic resonance } \\ \text { MRI } & \text { Magnetic resonance imaging } \\ \text { PDAC } & \text { Pancreatic ductal adenocarcinoma } \\ \text { SPACE } & \text { Serial pancreatic juice aspiration cytologic } \\ & \text { examination } \\ \text { UICC } & \text { Union for International Cancer Control }\end{array}$

\section{Introduction}

Pancreatic ductal adenocarcinoma (PDAC) is a rapidly progressing, highly lethal malignant disease that is difficult to detect in the early stages, due in part to its minimal symptoms early on [1]. PDAC is the fourth leading cause of cancer-related death in the USA and Japan, and the number of deaths is increasing annually worldwide [2]. PDAC is estimated to become the second leading cause of cancer mortality in the USA by 2030 [3]. According to the Japan Pancreatic Cancer Registry in 2012, the 5-year survival rate for patients with stage 0 and stage Ia PDAC in the Union for International Cancer Control (UICC) TNM classification is $85.8 \%$ and $68.7 \%$, respectively [4]. The prognosis is highly variable, even between those with stage 0 and Ia. Stage 0 PDAC is noninvasive cancer, namely, carcinoma in situ (CIS). To improve the prognosis of patients with PDAC, early-stage detection is essential. The frequency of stage 0 is approximately $1.7 \%$ of all cases and only $25 \%$ of these cases are symptomatic [4,5], which highlights the importance of surveillance for targeted patients during the asymptomatic phase. No effective strategies for detecting early-stage PDAC are established. Recent advances in imaging modalities, including contrast-enhanced computed tomography (CECT), magnetic resonance imaging (MRI), and endoscopic ultrasonography (EUS), allow for the observation of pancreatic CIS [5-12] and the potential detection of indirect imaging findings such as main pancreatic duct (MPD) dilatation, branch duct dilatation, substantial atrophy, and fat substitution of the pancreatic parenchyma for early diagnosis. Screening of patients with risk factors associated with PDAC, such as family history, hereditary pancreatitis, intraductal papillary mucinous neoplasm, diabetes, and smoking [13-19], will also enhance early detection. The aim of the present study was to assess the performance of diffusion-weighted MRI (DWI) for detecting early PDAC in patients with MPD stricture and no obvious pancreatic mass.

\section{Patients and methods}

\section{Patients}

Between March 2013 and January 2019, 225 patients were found to have an MPD stricture on images obtained by various modalities, including CECT, MRI, and EUS. Among these 225 patients, those with inflammatory and postoperative diseases, including chronic pancreatitis, autoimmune pancreatitis, trauma, and postoperative anastomotic stricture, were excluded. Those with clear occlusion of the MPD by tumors were also excluded. Finally, 37 patients with a localized MPD stricture and no obvious pancreatic mass were retrospectively enrolled (Fig. 1). All authors had access to the study data and reviewed and approved the final manuscript.

\section{Study design}

This retrospective study was conducted at a single center. The study was approved by the institutional review board and registered at the University Hospital Medical Information Network (UMIN000039623). The patients' informed consent was waived by the institutional review board.

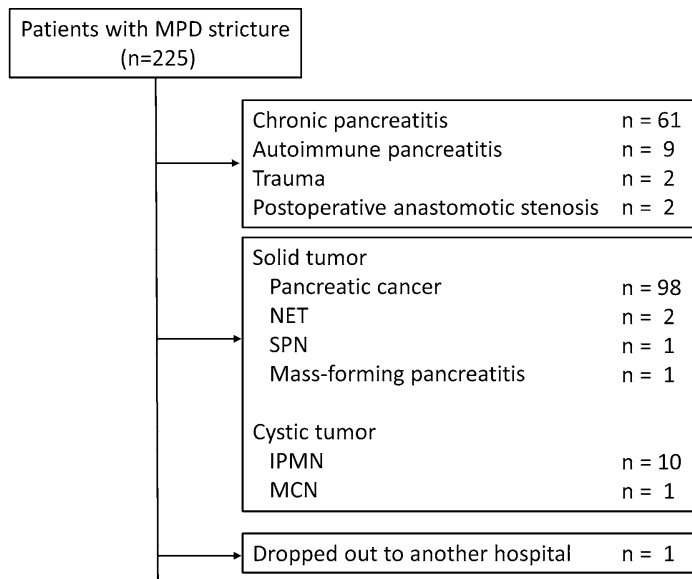

Localized stricture of MPD without obvious mass in the pancreas $(n=37)$

Fig. 1 Flowchart of patients throughout the study 


\section{Algorithm used in this study}

The study algorithm is shown in Fig. 2. All patients underwent endoscopic retrograde cholangiopancreatography (ERCP), and brush sampling with cytology and serial pancreatic juice aspiration cytologic examination (SPACE) via endoscopic naso-pancreatic drainage (ENPD). Patients diagnosed with malignancy confirmed by cytology underwent surgical resection. The remaining patients were followed by repeating CECT, MRI, and ERCP.

\section{Techniques and image evaluation}

\section{CT}

Multidetector CT (MDCT) examinations were performed using a 64-detector row CT scanner (Aquilion, Toshiba Medical, Japan). The nonionic contrast agent iodixanol (Iopamidol, $300 \mathrm{mg}$ iodine/mL; Fuji Pharma Co., Ltd., Japan) was used at a dose of $1.0-1.9 \mathrm{~mL} / \mathrm{kg}$ with a $2.2-3.3 \mathrm{~mL} / \mathrm{s}$ flow rate. The MDCT acquisition parameters were tube voltage, $120 \mathrm{kVp}$; tube current, auto-adjust; slice thickness, $2.0 \mathrm{~mm}$; reconstruction interval, $0 \mathrm{~mm}$; pitch factor, 0.844. CECT images were obtained at 35,50 , and $180 \mathrm{~s}$ after injection of the contrast agent. All CT imaging data were reviewed on a picture archiving and communication system workstation monitor (SYNAPS; Fujifilm Medical Systems, Japan).
MRI

MRI was performed with an InteraAchieva (Philips Healthcare, Netherlands), which is a 1.5 Tesla whole-body MRI system, and a 16-channel phased array coil as the receiver coil. DWI was performed with respiratory triggering. Apparent diffusion coefficient (ADC) values were calculated by DWI with $b$ values of 0 and $1000 \mathrm{~s} / \mathrm{mm}^{2}$. Frequency-selective fat saturation was used to reduce chemical shift artifacts. Pulse sequence parameters were as follows: repetition time/echo time, 1529/73 ms; field of view, $350 \mathrm{~mm}$; matrix, $96 \times 134$; number of signals acquired, 6 ; section thickness, $5 \mathrm{~mm}$; section gap, $0.5 \mathrm{~mm}$; receiver bandwidth, $2301 \mathrm{~Hz}$ per pixel; and the acquisition time ranged from 3 to $4 \mathrm{~min}$ depending on the patient's respiratory rhythm. The clinical MRI study also included T1-weighted gradient-echo MRI (183/4.6; flip angle $90^{\circ}$; field of view, $350 \mathrm{~mm}$; matrix, $256 \times 206$; number of signals acquired, 1 ; section thickness, $5 \mathrm{~mm}$; section gap, $0.5 \mathrm{~mm}$; acceleration factor, 2), and breath-hold single-shot T2-weighted image (6636/80; flip angle $90^{\circ}$; echo train length, 70; field of view, $350 \mathrm{~mm}$; matrix, $320 \times 256$; number of signals acquired, 1 ; section thickness, $5 \mathrm{~mm}$; section gap, $0.5 \mathrm{~mm}$; acceleration factor, 2), and breath-hold 2-dimensional magnetic resonance cholangiopancreatography $\left(10,979 / 500\right.$; flip angle $90^{\circ}$; echo train length, 101; field of view, $280 \mathrm{~mm}$; matrix, $256 \times 206$; number of signals acquired, 1 ; section thickness, $5 \mathrm{~mm}$; section gap, $-1.0 \mathrm{~mm}$; acceleration factor, 2). All MRI data

Fig. 2 Study algorithm

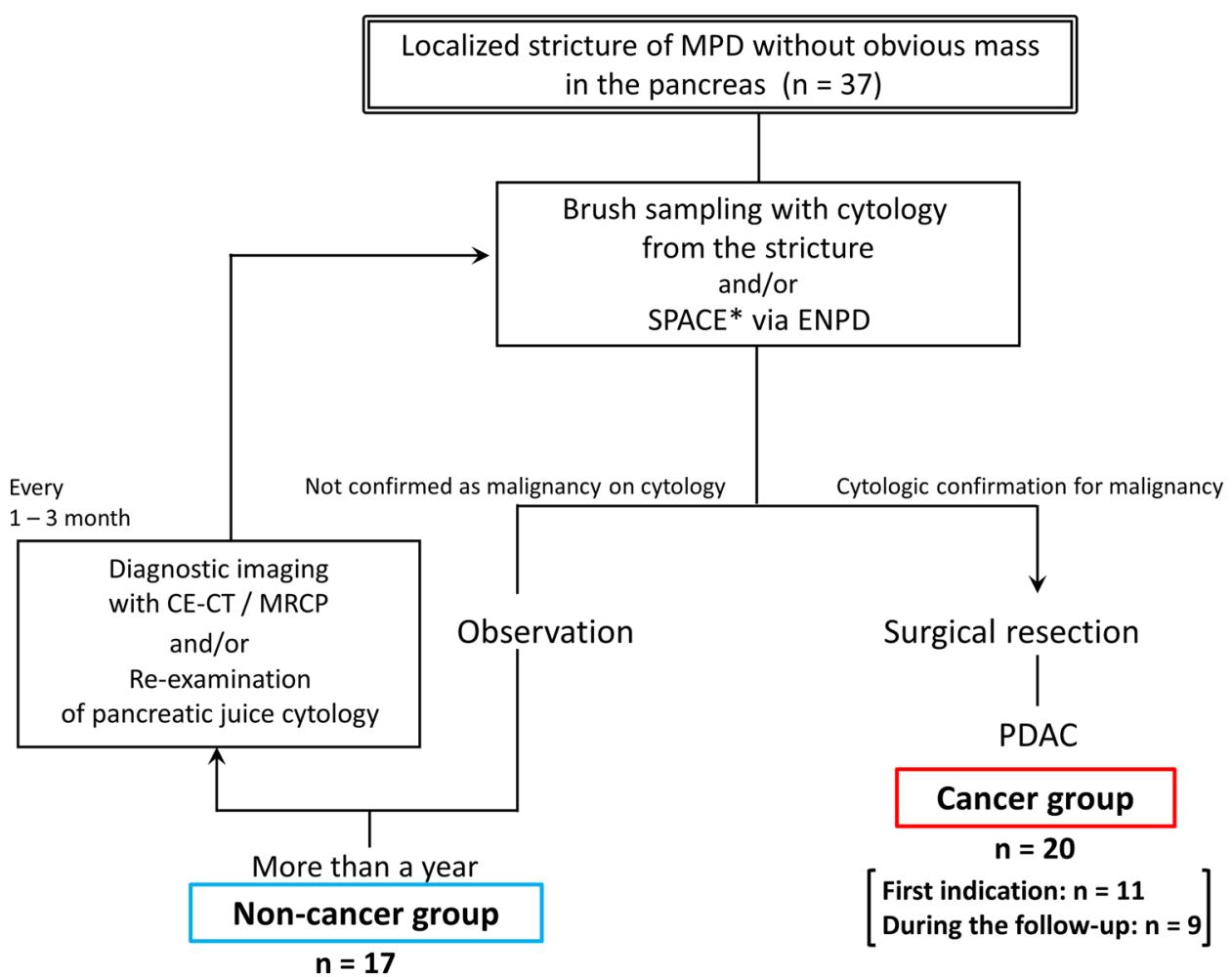


were reviewed on the SYNAPS system (Fujifilm Medical Systems).

\section{EUS procedures}

Gastroenterologists well trained in EUS performed the EUS examinations. See the Supplement for details. The pancreas was examined for the presence and size of focal lesions, such as a mass, nodule, small low echoic area, or cyst. Lesions (i.e., nodules or solid masses) were measured in 2 dimensions and characterized by shape, border, echogenicity, heterogeneity, and location. The pancreatic parenchyma and duct were assessed for changes of early chronic pancreatitis according to international consensus statements [20]. The MPD diameter was measured at the proximal and distal sides of the pancreas around the stricture.

\section{ERCP and cytologic examination procedures}

Details of the ERCP procedures are provided in the Supplement. When an MPD stricture was confirmed by pancreatography, brush sampling with cytology was performed and an ENPD tube was placed around the stricture site. SPACE was performed using samples obtained via the ENPD tube at least 6 times in 1 week.

\section{Image analysis}

Two experienced radiologists (K.S. and S.Y.), both with more than 5 years of experience reading abdominal $\mathrm{CT}$ and magnetic resonance (MR) images, independently interpreted the CECT and MR images. They were blinded to all clinical information and the final diagnosis. The readers noted the presence or absence of a pancreatic solid mass lesion, MPD stricture with proximal dilation, and pancreatic cyst in all CT and MR images.

The shape of the duct transition (smoothly tapered versus abrupt), maximum diameter of the MPD dilatation, presence of focal fatty changes in the parenchyma, and delayed enhancement were evaluated from CT images according to previous reports [5, 21]. MPD dilatation was considered present when the maximum MPD diameter was $\geq 2.5 \mathrm{~mm}$ [22].

The DWI signal intensity was classified on the basis of a qualitative evaluation according to the presence or absence of a hyperintensity lesion compared with the surrounding pancreas. If high signal intensity on diffusion-weighted (DW) images was observed, ADC values were measured for quantitative evaluation. The ADC values were calculated using an operator-defined region-of-interest around the caliber change point. Patients with diffuse high signal intensity on the caudal side due to obstructive pancreatitis (at the distal side of the MPD stricture with a signal intensity difference from the normal-appearing pancreatic tissue) rather than an MPD stricture were not included.

DWI data were reviewed with reference to images from other MRI sequences, such as T1- and T2-weighted images. The presence of obstructive pancreatitis was also evaluated on MR images.

The mean of the values scored by the two radiologists was adopted for quantitative data (i.e., maximum MPD diameter and $A D C$ values). When the $C T$ and MR images were interpreted differently by two evaluators, a final decision was reached by consulting with a third radiologist (O.R.).

EUS images were evaluated by a single gastroenterologist (A.K.) for the presence of a mass, early chronic pancreatitis in the normal parenchyma, and a hypoechoic area around the stricture not recognized as a mass.

\section{Study definitions}

Suspicion of malignancy or malignancy was diagnosed according to the Papanicolaou classification on the basis of cytologic confirmation and patients diagnosed with malignancy underwent surgical resection. The final diagnosis was made following histologic confirmation of PDAC obtained by surgical resection.

The malignant group was defined by histologic confirmation of a surgical specimen. The non-malignant group was defined by the absence of cytologic confirmation of malignancy and followed up for at least 1 year with no remarkable changes observed using either imaging modality. Clinical T factors of pathologic evaluation were determined according to the UICC 8th edition [23].

\section{Statistical analysis}

Categorical parameters were compared using the chi-square test and Fisher exact test, and continuous variables were compared using the Student $t$ test and percentages with a 95\% confidence interval. Cumulative survival was estimated by Kaplan-Meier analysis, and curves were compared by the log-rank test. All statistical analyses were performed with JMP version 13.0 (SAS Institute, Cary, NC, USA), with $P<0.05$ considered significant.

\section{Results}

\section{Patient characteristics}

Of the 37 patients enrolled in this study, 20 patients had confirmed malignancy (cancer group) and 17 were classified into the non-cancer group. The demographic data are shown in Table 1. The 2 groups did not differ significantly in age, MPD stricture location, or PDAC risk factors, but the sex 
Table 1 Clinical characteristics of enrolled patients

\begin{tabular}{llll}
\hline & $\begin{array}{l}\text { Cancer group } \\
(n=20)\end{array}$ & $\begin{array}{l}\text { Non-cancer group } \\
(n=17)\end{array}$ & $P$ value \\
\hline Sex (male/female) & $14 / 6$ & $5 / 12$ & 0.02 \\
Median age, year (range) & $68.5(36-86)$ & $70(49-84)$ & 0.62 \\
Symptoms, $n$ (\%) & $4(20)$ & $10(58.8)$ & 0.02 \\
Abdominal pain & 4 & 6 & \\
Back pain & 0 & 2 & \\
Other & 0 & 2 & 0.84 \\
Serum CEA level, ng/mL, median (range) & $2.5(1.9-4.5)$ & $3.5(2.0-9.2)$ & 0.07 \\
Serum CA19-9 level, U/mL, median (range) & $41.7(<2.0-511.2)$ & $7.2(<2.0-91.7)$ & $<0.01$ \\
Follow-up duration, months, median (range)* & $9.4(1.9-43.1)$ & $53.3(13.8-99.6)$ & 0.80 \\
Location of MPD stricture, head/body/tail, $n$ & $8 / 4 / 8$ & $5 / 4 / 8$ & 0.11 \\
Risk factors, n (\%)** & $18(90)$ & $11(64.7)$ & 0.61 \\
DM & 3 & 1 & $<0.01$ \\
Smoking & 13 & 2 & 0.48 \\
IPMN & 5 & 7 & - \\
Chronic pancreatitis & 0 & 0 & 0.17 \\
Heavy alcohol consumption & 8 & 3 & 0.29 \\
Obesity & 7 & 3 & 1.00 \\
Family history of PDAC & 2 & 1 & \\
\hline
\end{tabular}

$M P D$ main pancreatic duct, $D M$ diabetes mellitus, $I P M N$ intraductal papillary mucinous neoplasm, $P D A C$ pancreatic ductal adenocarcinoma

* Observation period of cancer group was the duration between the initial diagnosis and the time of cancer diagnosis of followed 9 patients

** Some cases had multiple risk factors predominance and rate of symptoms differed significantly between groups.

\section{Findings of each diagnostic imaging modality}

Table 2 shows the CECT, MRI, and EUS findings. CECT revealed no obvious solid mass in either group. The proximal dilated MPD diameter and number of focal fatty changes of the pancreatic parenchyma, delayed enhancement, existence of a pancreatic cyst, and the MPD stricture type were not significantly different between the two groups.

MRI revealed no obvious solid mass in either group. Areas of high signal intensity in DWI differed significantly between the two groups $(P<0.01)$. One false positive case in the non-cancer group on the basis of the DW image had a mean ADC value of 1.27, but close follow-up was selected because no malignancy was confirmed on cytologic examination and no changes were observed over 51.6 months.

For quantitative analysis, the ADC was measured in 13 patients in the cancer group and 1 patient in the non-cancer group (Table 3). ADC values did not differ significantly between groups $(P=0.95)$.

EUS images showed no obvious solid mass in either group. An indistinct and small hypoechoic area, however, was detected in $70 \%$ of patients in the cancer group and $41.2 \%$ in the non-cancer group.
A typical case is shown in Fig. 3. Focal pancreatic parenchymal atrophy and an MPD stricture without an obvious solid mass were visible on CT. DWI high signal intensity and an elevated ADC value were observed around the stricture. ERCP showed an MPD stricture in the tail of the pancreas, and the results of brush sampling with cytology were suspicious for malignancy. Distal pancreatectomy was performed and pathologic examination of the resected specimen indicated CIS (Fig. 4).

\section{Detailed characteristics of the cancer group}

Surgical resection was performed in all patients in the cancer group. The $\mathrm{T}$ factors of pathologic evaluation are shown in Table 4. The timing of the surgical resection varied, even for those with CIS. Of the 20 patients in the cancer group, 11 were diagnosed with PDAC at the first indication and 9 were diagnosed during the follow-up. The median follow-up period for the diagnosis of PDAC was 9.4 (range: 1.9-43.1) months in the follow-up group (Table 1). The prognosis did not differ between patients diagnosed at the first indication and those diagnosed during the follow-up ( $P=0.59$; Fig. 5).

Among the 20 patients in the cancer group, 17 were diagnosed with malignancy by cytologic analysis. Of these 17 cases, 6 were diagnosed by both brush cytology and SPACE, 5 were diagnosed by brush cytology alone, and 6 
Table 2 Imaging modalities and findings

\begin{tabular}{llll}
\hline Modalities and findings & $\begin{array}{l}\text { Cancer group } \\
(n=20)\end{array}$ & $\begin{array}{l}\text { Non-cancer group } \\
(n=17)\end{array}$ & $P$ value \\
\hline CECT & & & - \\
Obvious solid mass & 0 & $17(100)$ & 1.00 \\
MPD stricture with proximal dilation & $20(100)$ & $11 / 6$ & 1.00 \\
MPD stricture shape, abrupt/smooth & $13 / 7$ & $4.3(2.5-10.0)$ & 0.79 \\
Proximal MPD diameter, mm, median (range) & $5.0(2.5-8.5)$ & $8(47.1)$ & 0.75 \\
Focal fatty changes of parenchyma & $11(55)$ & $8(47.1)$ & 1.00 \\
Delayed enhancement & $9(45)$ & $10(58.8)$ & 0.74 \\
Pancreatic cyst & $10(50)$ & & - \\
MR & & 0 & 1.00 \\
Obvious solid mass & 0 & $17(100)$ & 0.74 \\
MPD stricture with proximal dilation & $20(100)$ & $10(58.8)$ & 0.29 \\
Pancreatic cyst & $10(50)$ & $3(17.6)$ & $<0.01$ \\
Obstructive pancreatitis & $7(35)$ & $1(5.9)$ & - \\
High intensity on DW & $13(65)$ & & 0.10 \\
EUS & & 0 & 0.17 \\
Obvious solid mass & 0 & $7(41.2)$ & $4(23.5)$ \\
Small hypoechoic area & $14(70)$ & & \\
Early chronic pancreatitis & $10(50)$ & & \\
\hline
\end{tabular}

Values are $n(\%)$ unless otherwise defined

$C E C T$ contrast-enhanced computed tomography, $M P D$ main pancreatic duct, $M R$ magnetic resonance, $D W$ diffusion weighted, EUS endoscopic ultrasonography
Table 3 Quantitative analysis of diffusion-weighted image

\begin{tabular}{llll}
\hline Case No & Pathologic T stage & Reader 1 & Reader 2 \\
\hline 1 & Tis & 1.65 & 1.62 \\
2 & Tis & 1.78 & 1.43 \\
3 & Tis & 1.39 & 1.05 \\
4 & Tis & 1.67 & 1.94 \\
5 & Tis & 1.02 & 1.02 \\
6 & T1b & 1.21 & 1.18 \\
7 & T1b & 1.22 & 1.03 \\
8 & T1c & 1.37 & 1.28 \\
9 & T1c & 2.02 & 1.68 \\
10 & T1c & 1.29 & 1.34 \\
11 & T1c & 1.40 & 1.48 \\
12 & T2 & 1.50 & 1.28 \\
13 & T3 & 1.24 & 1.22 \\
14 & Non-cancer group & 1.26 & 1.27 \\
\hline
\end{tabular}

$\mathrm{ADC}$ values are in units of $\times 10^{-3} \mathrm{~mm}^{2} / \mathrm{s}$

were diagnosed by SPACE alone. As to the other 3 patients of the 20 , the result of repeated cytologic analysis suggested malignancy, and although the results were inconclusive, the patients with clinically diagnosed with malignancy based on their cytology result and the shape of the pancreatic duct stricture, and underwent surgery during the follow-up period.

\section{Discussion}

This study is the first to describe DWI high signal intensity as a useful finding for detecting early-stage PDAC. Importantly, areas of high signal intensity in DW images were even observed in $71.4 \%$ of patients with CIS.

Multiple centers worldwide have developed pancreatic screening programs to detect early-stage PDAC in select populations of high-risk individuals (HRIs) [17-19, 24-29]. According to the International Cancer of the Pancreas Screening Consortium, HRIs are defined as those with a defined genetic syndrome and those without a diagnosed syndrome but with familial pancreatic cancer [18, 19, 25]. The incidence of PDAC is also increasing in the general population and most cases of PDAC are not found in HRIs, emphasizing the need for nonselective screening. Based on current evidence targeting HRIs, MRI and EUS should be first-line tests for pancreatic surveillance. EUS and MRI, however, are not adequate for detecting small PDACs, including CIS, with a diameter less than $1 \mathrm{~cm}$, and there are few reports of early-stage PDAC detection due to the lack of effective imaging modalities and biomarkers for small PDAC and CIS [24, 30-32].

Some researchers focusing on small PDACs report that the most abnormal findings obtained using various diagnostic imaging modalities to detect early-stage PDAC are indirect findings, such as MPD dilatation or retention cysts, 


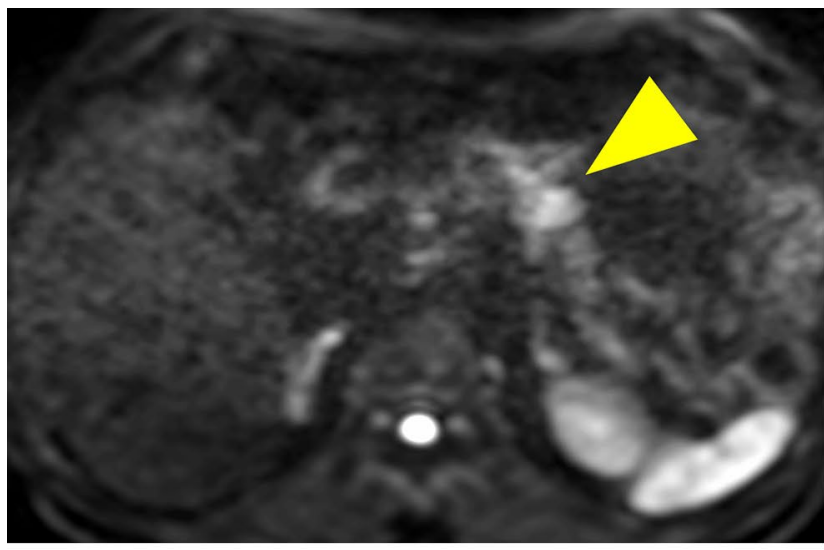

a

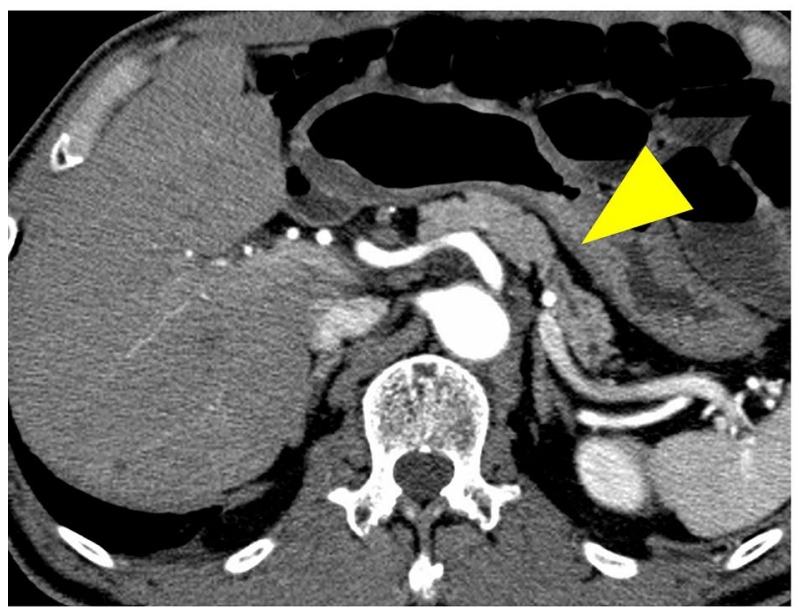

C

Fig. 3 a High signal intensity around the stricture in the diffusionweighted image (arrowhead). b apparent diffusion coefficient values by 2 readers were 1.65 and $1.62\left(\times 10^{-3} \mathrm{~mm}^{2} / \mathrm{s}\right)$, respectively. $\mathbf{c}$ Focal pancreatic parenchyma atrophy and main pancreatic duct stricture

with no direct findings of PDAC [5, 33, 34]. These findings suggest that attention should be focused on specific populations at increased risk for PDAC and the detection of indirect findings on diagnostic images in asymptomatic cases, and that further examination in such cases is important for early diagnosis of PDAC.

Several reports suggest that high signal intensity on DW images compared with surrounding tissue or benign lesions indicates the presence of PDAC [35-43]. Some tumors of a certain size show hyperintensity on DW images, whereas small tumors, especially those $<1 \mathrm{~cm}$, do not. Some researchers report that localized fatty changes of the pancreatic parenchyma observed in CT images may be a feature of CIS [5, 34]. Our findings, however, demonstrated that localized fatty changes were not a specific feature of CIS because $47.1 \%$ of patients in the non-cancer group showed this change, and no significant difference was detected between the cancer and non-cancer groups.

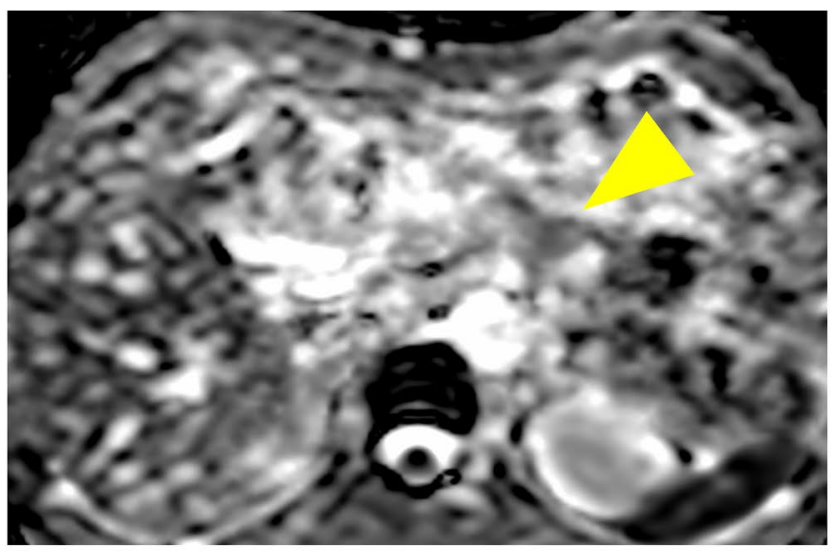

b

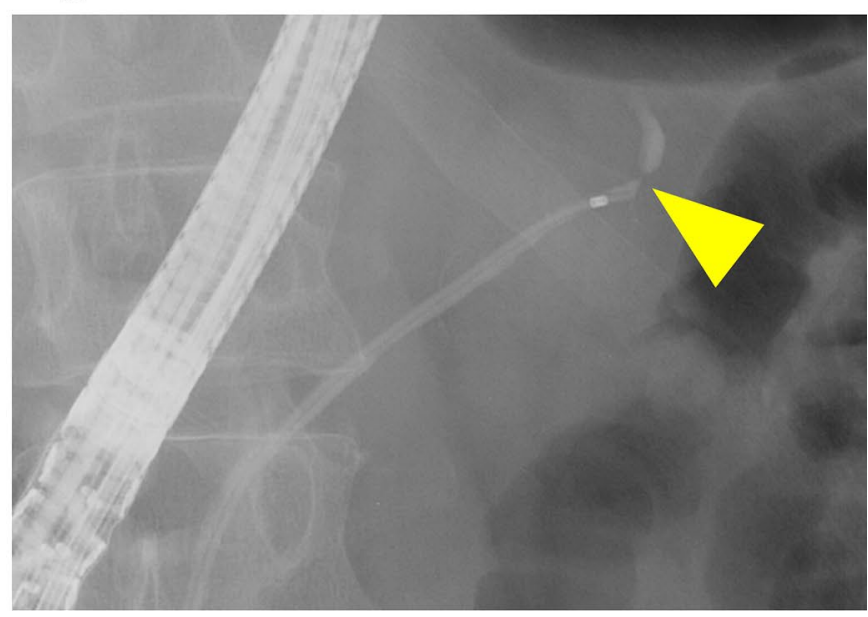

d

without a visible mass on computed tomography (arrowhead). d pancreatography shows a high-grade pancreatic duct stricture in the pancreatic tail

Localized pancreatitis with infiltration of inflammatory cells, fibrosis, and fatty infiltration is frequently observed in the parenchyma around CIS and atypical epithelium [34]. Thus, our finding that even CIS appeared as an area of hyperintensity indicates that hyperintensity does not reflect the tumor itself, but rather the surrounding inflammation and fibrosis $[44,45]$. Supplementary Figure shows a case of CIS. High signal intensity on DW images indicated inflammation and fibrosis around the CIS lesion by pathologic analysis.

The most important factor in diagnosing early-stage PDAC is the confirmation of malignancy by cytologic examination. Previous reports indicate that cytologic examination of the pancreatic juice and brush sampling has a sensitivity of $33 \%-80 \%$ [46-51]. False-negative cases, however, remain a problem. In our study, cytologic diagnosis was positive in 11 of 20 patients $(55 \%)$ in the cancer group at the initial examination, and 3 cases in the follow-up group underwent surgical resection without 
Fig. 4 Resected pancreas with carcinoma in situ. High-grade pancreatic intraepithelial neoplasia in the periphery of the pancreas (hematoxylin \& eosin, orig. mag. 40X). a Main pancreatic duct is indicated by the arrowhead. b Area in the red box

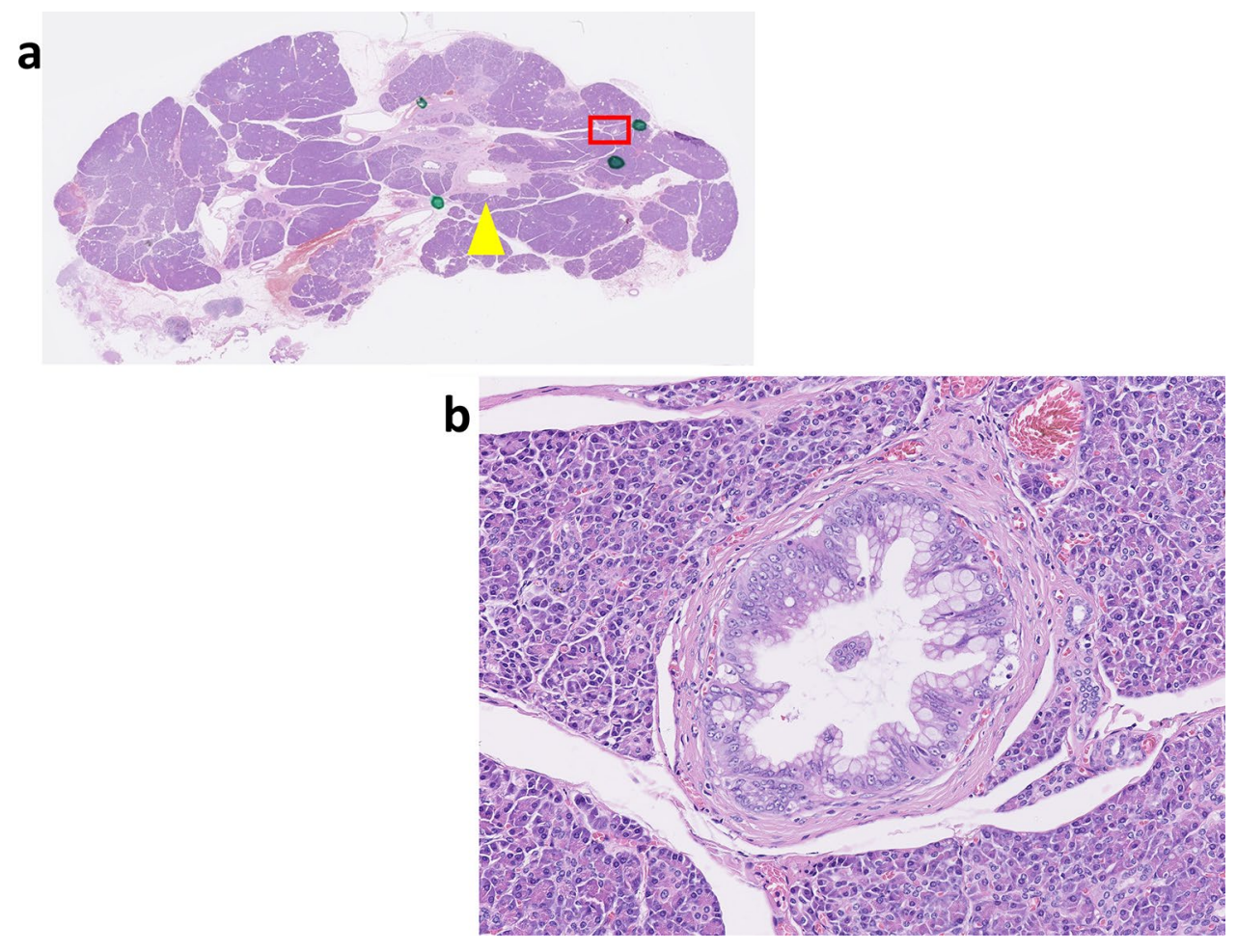

\begin{tabular}{llll}
\hline Pathologic T stage & $N(\%)$ & $\begin{array}{l}\text { Timing of PDAC diagnosis, } \\
\text { initial/follow-up }\end{array}$ & $\begin{array}{l}\text { High intensity } \\
\text { on DW, } n(\%)\end{array}$ \\
\hline Tis & $7(35)$ & $3 / 4$ & $5(71.4)$ \\
T1a $(\leq 5 \mathrm{~mm})$ & $2(10)$ & $2 / 0$ & 0 \\
T1b $(5 \mathrm{~mm}<$ tumor $<10 \mathrm{~mm})$ & $2(10)$ & $1 / 1$ & $2(100)$ \\
T1c $(1-2 \mathrm{~cm})$ & $5(25)$ & $2 / 3$ & $4(80)$ \\
T2 $(2 \mathrm{~cm}<$ and $\leq 4 \mathrm{~cm})$ & $3(15)$ & $2 / 1$ & $1(33.3)$ \\
T3 $(4 \mathrm{~cm}<)$ & $1(5)$ & $1 / 0$ & $1(100)$ \\
\hline
\end{tabular}

Table 4 Detailed staging factors of cancer group

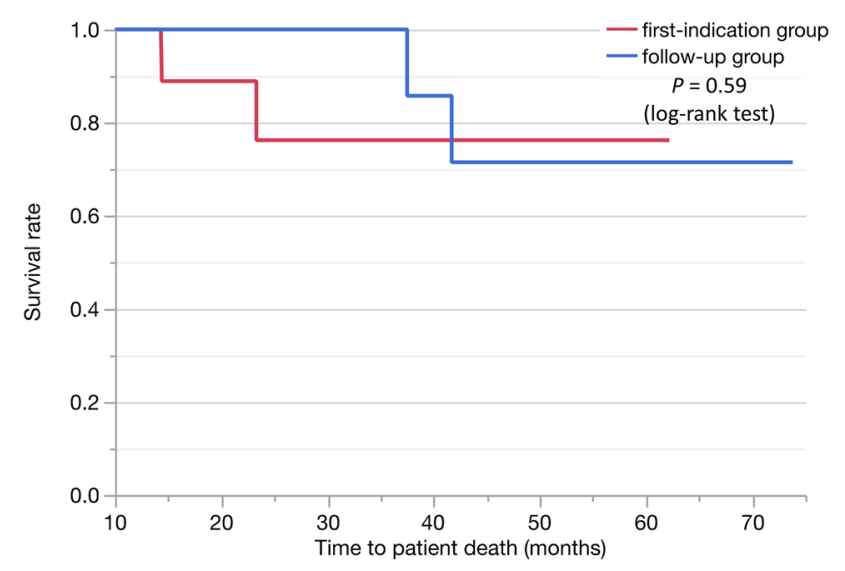

Fig. 5 Comparison of the prognosis for patients diagnosed at the first indication and those diagnosed during follow-up cytologic confirmation of malignancy. These 3 patients were clinically diagnosed with malignancy and surgery was performed after follow-up periods of 7.9, 30.2, and 43.1 months. All 3 cases were in the pT1 stage. Five patients in the follow-up group, other than four cases with CIS, might have been diagnosed at an earlier stage if the initial cytology-based diagnosis had been accurate. To increase the sensitivity of cytologic examination, some studies have analyzed the usefulness of repeated samplings evaluated by SPACE and secretin injection, but the sensitivity is at most $80 \%$ [51]. Therefore, high signal intensity on DW images, as reported here, is a highly useful finding for diagnosing early-stage PDAC, leading to a recommendation for surgical resection without cytologic confirmation. 
The present study has several limitations. First, the sample size was relatively small and retrospective studies are more prone to bias than prospective studies. A prospective study with a larger number of patients should be performed to confirm our findings. Second, PDAC may also arise later in the non-cancer group, although no PDAC was detected in those patients during a median follow-up duration of 53 months. A longer follow-up period is needed to rule out this possibility. Third, areas of inflammation, such as obstructive pancreatitis, may also appear as high signal intensity on DW images. Patients with diffuse high signal intensity on the caudal side rather than an MPD stricture were excluded, but it is difficult to exclude them completely because pancreatitis sometimes appears mottled and heterogeneous. Because the images were interpreted by two independent radiologists, however, the possibility of obstructive pancreatitis was minimized. Fourth, some patients in the cancer group were found to be in an advanced stage, which may be due to the rapid progression of PDAC. To address this possibility, the waiting time until surgery should be reduced, and ideally a test should be developed that can identify tumors at the cellular level.

In conclusion, patients with an MPD stricture should undergo MR imaging and evaluation of areas with high signal intensity on DW images for detection of early-stage PDAC. Surgical resection should be considered for some patients showing high signal intensity areas on DW images, even without prior pathologic confirmation of PDAC.

Supplementary Information The online version contains supplementary material available at https://doi.org/10.1007/s00261-021-03199-1.

\begin{abstract}
Author contributions $\mathrm{AK}$ and $\mathrm{YM}$ had full access to all of the data in the study and take responsibility for the integrity of the data and the accuracy of the data analysis. Study concept and design: AK and YM. Acquisition of data: AK, YM, KI, and SA. Analysis and interpretation of data: YM, AK, YS, SK, SI, and RO. Drafting of the manuscript: YM and AK. Critical revision of the manuscript for important intellectual content: AK and SY. Statistical analysis: AK.
\end{abstract}

Funding There was no source of financial support for this study.

\section{Declarations}

Conflict of interest The authors disclose no conflicts.

Open Access This article is licensed under a Creative Commons Attribution 4.0 International License, which permits use, sharing, adaptation, distribution and reproduction in any medium or format, as long as you give appropriate credit to the original author(s) and the source, provide a link to the Creative Commons licence, and indicate if changes were made. The images or other third party material in this article are included in the article's Creative Commons licence, unless indicated otherwise in a credit line to the material. If material is not included in the article's Creative Commons licence and your intended use is not permitted by statutory regulation or exceeds the permitted use, you will need to obtain permission directly from the copyright holder. To view a copy of this licence, visit http://creativecommons.org/licenses/by/4.0/.

\section{References}

1. Kamisawa T, Wood LD, Itoi T, Takaori K (2016) Pancreatic cancer. Lancet. 388(10039):73-85. https://doi.org/10.1016/S01406736(16)00141-0

2. Siegel RL, Miller KD, Jemal A (2018) Cancer statistics, 2018. CA Cancer J Clin. 68(1):7-30. https://doi.org/10.3322/caac.21442

3. Rahib L, Smith BD, Aizenberg R, Rosenzweig AB, Fleshman JM, Matrisian LM (2014) Projecting cancer incidence and deaths to 2030: the unexpected burden of thyroid, liver, and pancreas cancers in the United States. Cancer Res. 74(11):2913-2921. https:// doi.org/10.1158/0008-5472.CAN-14-0155

4. Egawa S, Toma H, Ohigashi H, Okusaka T, Nakao A, Hatori T, Maguchi H, Yanagisawa A, Tanaka M (2012) Japan Pancreatic Cancer Registry; 30th year anniversary: Japan Pancreas Society. Pancreas. 41(7):985-992. https://doi.org/10.1097/MPA.0b013 e318258055c

5. Kanno A, Masamune A, Hanada K, Maguchi H, Shimizu Y, Ueki T, Hasebe O, Ohtsuka T, Nakamura M, Takenaka M, Kitano M, Kikuyama M, Gabata T, Yoshida K, Sasaki T, Serikawa M, Furukawa T, Yanagisawa A, Shimosegawa T, Japan Study Group on the Early Detection of Pancreatic C (2018) Multicenter study of early pancreatic cancer in Japan. Pancreatology. 18(1):61-67. https://doi.org/10.1016/j.pan.2017.11.007

6. Sakamoto H, Kitano M, Dote K, Tchikugo T, Takeyama Y, Kudo M (2008) In situ carcinoma of pancreas diagnosed by EUS-FNA. Endoscopy. 40 Suppl 2:E15-16. https://doi.org/10. 1055/s-2007-966708

7. Seki M, Ninomiya E, Hayashi K, Gotoh H, Koga R, Saiura A, Yamada K, Katori M, Kato Y, Okamura H (2010) Widespread and multifocal carcinomas in situ (CISs) through almost the entire pancreas: report of a case with preoperative cytological diagnosis. Langenbecks Arch Surg. 395(5):589-592. https://doi.org/10.1007/ s00423-009-0579-4

8. Inoue $\mathrm{H}$, Katurahara M, Hamada $\mathrm{Y}$, Ninomiya $\mathrm{K}$, Tano $\mathrm{S}$, Takayama R, Nojiri K, Tameda M, Horiki N, Takei Y (2012) Hemosuccus pancreaticus caused by in situ carcinoma of the pancreas. Endoscopy. 44 Suppl 2 UCTN:E336-337. https://doi.org/10. 1055/s-0032-1309863

9. Satoh T, Kikuyama M, Kawaguchi S, Kanemoto H, Muro H, Hanada K (2017) Acute pancreatitis-onset carcinoma in situ of the pancreas with focal fat replacement diagnosed using serial pancreatic-juice aspiration cytologic examination (SPACE). Clin J Gastroenterol. 10(6):541-545. https://doi.org/10.1007/ s12328-017-0776-6

10. Yamao K, Takenaka M, Nakai A, Omoto S, Kamata K, Minaga K, Miyata T, Imai H, Sakurai T, Watanabe T, Nishida N, Matsumoto I, Takeyama Y, Chikugo T, Kudo M (2017) Detection of HighGrade Pancreatic Intraepithelial Neoplasia without Morphological Changes of the Main Pancreatic Duct over a Long Period: Importance for Close Follow-Up for Confirmation. Oncology. 93 Suppl 1:81-86. https://doi.org/10.1159/000481237

11. Miyata T, Takenaka M, Omoto S, Kamata K, Minaga K, Yamao K, Imai H, Kudo M (2017) A Case of Pancreatic Carcinoma in situ Diagnosed by Repeated Pancreatic Juice Cytology. Oncology. 93 Suppl 1:98-101. https://doi.org/10.1159/000481240

12. Yokode M, Akita M, Fujikura K, Kim MJ, Morinaga Y, Yoshikawa S, Terada T, Matsukiyo H, Tajiri T, Abe-Suzuki S, Itoh T, Hong SM, Zen Y (2018) High-grade PanIN presenting with localised stricture of the main pancreatic duct: A clinicopathological 
and molecular study of 10 cases suggests a clue for the early detection of pancreatic cancer. Histopathology. 73(2):247-258. https://doi.org/10.1111/his.13629

13. Genkinger JM, Spiegelman D, Anderson KE, Bergkvist L, Bernstein L, van den Brandt PA, English DR, Freudenheim JL, Fuchs CS, Giles GG, Giovannucci E, Hankinson SE, Horn-Ross PL, Leitzmann M, Mannisto S, Marshall JR, McCullough ML, Miller AB, Reding DJ, Robien K, Rohan TE, Schatzkin A, Stevens VL, Stolzenberg-Solomon RZ, Verhage BA, Wolk A, Ziegler RG, Smith-Warner SA (2009) Alcohol intake and pancreatic cancer risk: a pooled analysis of fourteen cohort studies. Cancer Epidemiol Biomarkers Prev. 18(3):765-776. https://doi.org/10.1158/ 1055-9965.EPI-08-0880

14. Del Chiaro M, Zerbi A, Capurso G, Zamboni G, Maisonneuve P, Presciuttini S, Arcidiacono PG, Calculli L, Falconi M, Italian Registry for Familial Pancreatic C (2010) Familial pancreatic cancer in Italy. Risk assessment, screening programs and clinical approach: a position paper from the Italian Registry. Dig Liver Dis. 42(9):597-605. https://doi.org/10.1016/j.dld.2010.04.016

15. Goral V (2015) Pancreatic Cancer: Pathogenesis and Diagnosis. Asian Pac J Cancer Prev. 16(14):5619-5624. https://doi.org/10. 7314/apjcp.2015.16.14.5619

16. Ilic M, Ilic I (2016) Epidemiology of pancreatic cancer. World J Gastroenterol. 22(44):9694-9705. https://doi.org/10.3748/wjg. v22.i44.9694

17. Paiella S, Salvia R, De Pastena M, Pollini T, Casetti L, Landoni L, Esposito A, Marchegiani G, Malleo G, De Marchi G, Scarpa A, D’Onofrio M, De Robertis R, Pan TL, Maggino L, Andrianello S, Secchettin E, Bonamini D, Melisi D, Tuveri M, Bassi C (2018) Screening/surveillance programs for pancreatic cancer in familial high-risk individuals: A systematic review and proportion meta-analysis of screening results. Pancreatology. 18(4):420-428. https://doi.org/10.1016/j.pan.2018.04.002

18. Paiella S, Capurso G, Cavestro GM, Butturini G, Pezzilli R, Salvia R, Signoretti M, Crippa S, Carrara S, Frigerio I, Bassi C, Falconi M, Iannicelli E, Giardino A, Mannucci A, Laghi A, Laghi L, Frulloni L, Zerbi A (2019) Results of First-Round of Surveillance in Individuals at High-Risk of Pancreatic Cancer from the AISP (Italian Association for the Study of the Pancreas) Registry. Am J Gastroenterol. 114(4):665-670. https://doi.org/10. 1038/s41395-018-0414-z

19. Canto MI, Harinck F, Hruban RH, Offerhaus GJ, Poley JW, Kamel I, Nio Y, Schulick RS, Bassi C, Kluijt I, Levy MJ, Chak A, Fockens P, Goggins M, Bruno M, International Cancer of Pancreas Screening C (2013) International Cancer of the Pancreas Screening (CAPS) Consortium summit on the management of patients with increased risk for familial pancreatic cancer. Gut. 62(3):339347. https://doi.org/10.1136/gutjnl-2012-303108

20. Whitcomb DC, Shimosegawa T, Chari ST, Forsmark CE, Frulloni L, Garg P, Hegyi P, Hirooka Y, Irisawa A, Ishikawa T, Isaji S, Lerch MM, Levy P, Masamune A, Wilcox CM, Windsor J, Yadav D, Sheel A, Neoptolemos JP, Working Group for the International Consensus Guidelines for Chronic P (2018) International consensus statements on early chronic Pancreatitis. Recommendations from the working group for the international consensus guidelines for chronic pancreatitis in collaboration with The International Association of Pancreatology, American Pancreatic Association, Japan Pancreas Society, PancreasFest Working Group and European Pancreatic Club. Pancreatology. https://doi.org/10.1016/j. pan.2018.05.008

21. Kim SW, Kim SH, Lee DH, Lee SM, Kim YS, Jang JY, Han JK (2017) Isolated Main Pancreatic Duct Dilatation: CT Differentiation Between Benign and Malignant Causes. AJR Am J Roentgenol. 209(5):1046-1055. https://doi.org/10.2214/AJR.17.17963

22. Fukukura Y, Fujiyoshi F, Sasaki M, Nakajo M (2002) Pancreatic duct: morphologic evaluation with MR cholangiopancreatography after secretin stimulation. Radiology. 222(3):674-680. https://doi. org/10.1148/radiol.2223010684

23. James D. Brierley MKG, Christian Wittekind (2018) TNM Classification of Malignant nant Tumors. 8th ed. New York, NY: Wiley.

24. Corral JE, Mareth KF, Riegert-Johnson DL, Das A, Wallace MB (2019) Diagnostic Yield From Screening Asymptomatic Individuals at High Risk for Pancreatic Cancer: A Meta-analysis of Cohort Studies. Clin Gastroenterol Hepatol. 17(1):41-53. https://doi.org/ 10.1016/j.cgh.2018.04.065

25. Goggins M, Overbeek KA, Brand R, Syngal S, Del Chiaro M, Bartsch DK, Bassi C, Carrato A, Farrell J, Fishman EK, Fockens P, Gress TM, van Hooft JE, Hruban RH, Kastrinos F, Klein A, Lennon AM, Lucas A, Park W, Rustgi A, Simeone D, Stoffel E, Vasen HFA, Cahen DL, Canto MI, Bruno M, International Cancer of the Pancreas Screening c (2020) Management of patients with increased risk for familial pancreatic cancer: updated recommendations from the International Cancer of the Pancreas Screening (CAPS) Consortium. Gut. 69(1):7-17. https://doi.org/10.1136/ gutjnl-2019-319352

26. Dudley B, Brand RE (2019) Pancreatic Cancer Surveillance: Who, When, and How. Curr Treat Options Gastroenterol. 17(4):681691. https://doi.org/10.1007/s11938-019-00247-0

27. O'Neill RS, Meiser B, Emmanuel S, Williams DB, Stoita A (2020) Long-term positive psychological outcomes in an Australian pancreatic cancer screening program. Fam Cancer. 19(1):2335. https://doi.org/10.1007/s10689-019-00147-3

28. McGuigan A, Kelly P, Turkington RC, Jones C, Coleman HG, McCain RS (2018) Pancreatic cancer: A review of clinical diagnosis, epidemiology, treatment and outcomes. World J Gastroenterol. 24(43):4846-4861. https://doi.org/10.3748/wjg.v24.i43.4846

29. Latenstein AEJ, van der Geest LGM, Bonsing BA, Groot Koerkamp B, Haj Mohammad N, de Hingh I, de Meijer VE, Molenaar IQ, van Santvoort HC, van Tienhoven G, Verheij J, Vissers PAJ, de Vos-Geelen J, Busch OR, van Eijck CHJ, van Laarhoven HWM, Besselink MG, Wilmink JW, Dutch Pancreatic Cancer G (2020) Nationwide trends in incidence, treatment and survival of pancreatic ductal adenocarcinoma. Eur J Cancer. 125:83-93. https://doi.org/10.1016/j.ejca.2019.11.002

30. Brentnall TA, Bronner MP, Byrd DR, Haggitt RC, Kimmey MB (1999) Early diagnosis and treatment of pancreatic dysplasia in patients with a family history of pancreatic cancer. Ann Intern Med. 131(4):247-255. https://doi.org/10.7326/0003-4819-1314-199908170-00003

31. Harinck F, Konings IC, Kluijt I, Poley JW, van Hooft JE, van Dullemen HM, Nio CY, Krak NC, Hermans JJ, Aalfs CM, Wagner A, Sijmons RH, Biermann K, van Eijck CH, Gouma DJ, Dijkgraaf MG, Fockens P, Bruno MJ, Dutch research group on pancreatic cancer surveillance in high-risk i (2016) A multicentre comparative prospective blinded analysis of EUS and MRI for screening of pancreatic cancer in high-risk individuals. Gut. 65(9):1505-1513. https://doi.org/10.1136/gutjnl-2014-308008

32. Potjer TP, Schot I, Langer P, Heverhagen JT, Wasser MN, Slater EP, Kloppel G, Morreau HM, Bonsing BA, de Vos Tot Nederveen Cappel WH, Bargello M, Gress TM, Vasen HF, Bartsch DK, Leiden Familial Pancreatic Cancer G, FaPaCa r (2013) Variation in precursor lesions of pancreatic cancer among high-risk groups. Clin Cancer Res. 19(2):442-449. https://doi.org/10.1158/10780432.CCR-12-2730

33. Iiboshi T, Hanada K, Fukuda T, Yonehara S, Sasaki T, Chayama K (2012) Value of cytodiagnosis using endoscopic nasopancreatic drainage for early diagnosis of pancreatic cancer: establishing a new method for the early detection of pancreatic carcinoma in situ. Pancreas. 41(4):523-529. https://doi.org/10.1097/MPA.0b013 e31823c0b05 
34. Hanada K, Amano H, Abe T (2017) Early diagnosis of pancreatic cancer: Current trends and concerns. Ann Gastroenterol Surg. 1(1):44-51. https://doi.org/10.1002/ags3.12004

35. Ichikawa T, Erturk SM, Motosugi U, Sou H, Iino H, Araki T, Fujii H (2007) High-b value diffusion-weighted MRI for detecting pancreatic adenocarcinoma: preliminary results. AJR Am J Roentgenol. 188(2):409-414. https://doi.org/10.2214/AJR.05.1918

36. Koh DM, Collins DJ (2007) Diffusion-weighted MRI in the body: applications and challenges in oncology. AJR Am J Roentgenol. 188(6):1622-1635. https://doi.org/10.2214/AJR.06.1403

37. Tsushima Y, Takano A, Taketomi-Takahashi A, Endo K (2007) Body diffusion-weighted MR imaging using high b-value for malignant tumor screening: usefulness and necessity of referring to T2-weighted images and creating fusion images. Acad Radiol. 14(6):643-650. https://doi.org/10.1016/j.acra.2007.02.006

38. Fattahi R, Balci NC, Perman WH, Hsueh EC, Alkaade S, Havlioglu N, Burton FR (2009) Pancreatic diffusion-weighted imaging (DWI): comparison between mass-forming focal pancreatitis (FP), pancreatic cancer (PC), and normal pancreas. J Magn Reson Imaging. 29(2):350-356. https://doi.org/10.1002/jmri.21651

39. Kartalis N, Lindholm TL, Aspelin P, Permert J, Albiin N (2009) Diffusion-weighted magnetic resonance imaging of pancreas tumours. Eur Radiol. 19(8):1981-1990. https://doi.org/10.1007/ s00330-009-1384-8

40. Fukukura Y, Takumi K, Kamimura K, Shindo T, Kumagae Y, Tateyama A, Nakajo M (2012) Pancreatic adenocarcinoma: variability of diffusion-weighted MR imaging findings. Radiology. 263(3):732-740. https://doi.org/10.1148/radiol.12111222

41. De Robertis R, Tinazzi Martini P, Demozzi E, Dal Corso F, Bassi C, Pederzoli P, D’Onofrio M (2015) Diffusion-weighted imaging of pancreatic cancer. World J Radiol. 7(10):319-328. https://doi. org/10.4329/wjr.v7.i10.319

42. Ma C, Li J, Boukar MB, Yang P, Wang L, Chen L, Su L, Qu J, Chen SY, Hao Q, Lu JP (2017) Optimized ROI size on ADC measurements of normal pancreas, pancreatic cancer and massforming chronic pancreatitis. Oncotarget. 8(58):99085-99092. https://doi.org/10.18632/oncotarget.18457

43. Park MJ, Kim YK, Choi SY, Rhim H, Lee WJ, Choi D (2014) Preoperative detection of small pancreatic carcinoma: value of adding diffusion-weighted imaging to conventional MR imaging for improving confidence level. Radiology. 273(2):433-443. https://doi.org/10.1148/radiol.14132563
44. Rebours V, Gaujoux S, d'Assignies G, Sauvanet A, Ruszniewski P, Levy P, Paradis V, Bedossa P, Couvelard A (2015) Obesity and Fatty Pancreatic Infiltration Are Risk Factors for Pancreatic Precancerous Lesions (PanIN). Clin Cancer Res. 21(15):3522-3528. https://doi.org/10.1158/1078-0432.CCR-14-2385

45. Zhou B, Wu D, Liu H, Du LT, Wang YS, Xu JW, Qiu FB, Hu SY, Zhan HX (2019) Obesity and pancreatic cancer: An update of epidemiological evidence and molecular mechanisms. Pancreatology. 19(7):941-950. https://doi.org/10.1016/j.pan.2019.08.008

46. Endo Y MT, Tamura H, Okuda S. ( 1974) Cytodiagnosis of pancreatic malignant tumors by aspiration, under direct vision, using a duodenal fiberscope. Gastroenterology. 67(5):944-951.

47. Hatfield AR, Smithies A, Wilkins R, Levi AJ (1976) Assessment of endoscopic retrograde cholangio-pancreatography (ERCP) and pure pancreatic juice cytology in patients with pancreatic disease. Gut. 17(1):14-21. https://doi.org/10.1136/gut.17.1.14

48. Mitchell ML, Carney CN (1985) Cytologic criteria for the diagnosis of pancreatic carcinoma. Am J Clin Pathol. 83(2):171-176. https://doi.org/10.1093/ajcp/83.2.171

49. McGuire DE, Venu RP, Brown RD, Etzkorn KP, Glaws WR, AbuHammour A (1996) Brush cytology for pancreatic carcinoma: an analysis of factors influencing results. Gastrointest Endosc. 44(3):300-304. https://doi.org/10.1016/s0016-5107(96)70168-2

50. Volmar KE, Vollmer RT, Routbort MJ, Creager AJ (2006) Pancreatic and bile duct brushing cytology in 1000 cases: review of findings and comparison of preparation methods. Cancer. 108(4):231238. https://doi.org/10.1002/cncr.21842

51. Mikata R, Ishihara T, Tada M, Tawada K, Saito M, Kurosawa J, Sugiyama H, Sakai Y, Tsuyuguchi T, Miyazaki M, Yokosuka O (2013) Clinical usefulness of repeated pancreatic juice cytology via endoscopic naso-pancreatic drainage tube in patients with pancreatic cancer. J Gastroenterol. 48(7):866-873. https://doi.org/10. 1007/s00535-012-0684-y

Publisher's Note Springer Nature remains neutral with regard to jurisdictional claims in published maps and institutional affiliations.

\section{Authors and Affiliations}

\section{Akira Kurita ${ }^{1,3}$ (1) $\cdot$ Yoshiharu Mori $^{1} \cdot$ Yuko Someya $^{2} \cdot$ Shigeto Kubo $^{2} \cdot$ Shunjiro Azuma ${ }^{1} \cdot$ Kosuke Iwano $^{1}$. Satoshi Ikeda ${ }^{2} \cdot$ Ryosuke Okumura $^{2} \cdot$ Shujiro Yazumi ${ }^{1}$}

Akira Kurita

kuritaaki1976@gmail.com

1 Department of Gastroenterology and Hepatology, Kitano Hospital, Tazuke Kofukai Medical Research Institute, 2-4-20 Ohgimachi, Kita-ku, Osaka 530-8480, Japan
2 Department of Diagnostic Imaging, Kitano Hospital, Tazuke Kofukai Medical Research Institute, 2-4-20 Ohgimachi, Kita-ku, Osaka 530-8480, Japan

3 Department of Gastroenterology and Hepatology, Rakuwakai Otowa Hospital, 2 Otowachinji-cho, Yamashina-ku, Kyoto 607-8062, Japan 